\title{
Cannibalism in Tyrannosaurus rex
}

\author{
Nicholas R. Longrich ${ }^{1 *}$, John R. Horner ${ }^{2}$, Gregory M. Erickson ${ }^{3}$, Philip J. Currie ${ }^{4}$
}

1 Department of Geology and Geophysics, Yale University, New Haven, Connecticut, United States of America, 2 Museum of the Rockies, Montana State University, Bozeman, Montana, United States of America, 3 Department of Biological Science, Florida State University, Tallahassee, Florida, United States of America, 4 Department of Biological Sciences, University of Alberta, Edmonton, Alberta, Canada

\begin{abstract}
Background: Tyrannosaurus rex was one of the largest terrestrial carnivores of all time, and consequently its ecology and diet have been the focus of much discussion. However, there is little direct evidence of diet or feeding habits in this species.

Methodology/Principal Findings: Examination of museum collections has revealed four specimens of Tyrannosaurus rex that bear tooth marks made by large, carnivorous dinosaurs. Because Tyrannosaurus is the only large carnivore known from the Late Maastrichtian of western North America, we infer that Tyrannosaurus made these tooth marks.

Conclusions/Significance: The marks are interpreted as feeding traces and these fossils therefore record instances of cannibalism. Given that this behavior has a low preservation potential, cannibalism seems to have been a surprisingly common behavior in Tyrannosaurus, and this behavior may have been relatively common in carnivorous dinosaurs.

Citation: Longrich NR, Horner JR, Erickson GM, Currie PJ (2010) Cannibalism in Tyrannosaurus rex. PLoS ONE 5(10): e13419. doi:10.1371/journal.pone.0013419

Editor: Andrew Allen Farke, Raymond M. Alf Museum of Paleontology, United States of America

Received February 23, 2010; Accepted September 3, 2010; Published October 15, 2010

Copyright: (C) 2010 Longrich et al. This is an open-access article distributed under the terms of the Creative Commons Attribution License, which permits unrestricted use, distribution, and reproduction in any medium, provided the original author and source are credited.

Funding: NRL was supported by an Alberta Ingenuity Graduate Research Fellowship, and a Yale Institute for Biospheric Studies Donnelley Fellowship. PJC was supported by the Natural Sciences and Engineering Research Council Canada, and N. Myrvold supported fieldwork by JRH. The funders had no role in study design, data collection and analysis, decision to publish, or preparation of the manuscript.

Competing Interests: The authors have declared that no competing interests exist.

* E-mail: nicholas.longrich@yale.edu
\end{abstract}

\section{Introduction}

The tyrannosaurids are a highly specialized group of carnivorous dinosaurs characterized by massive skulls, elongate hindlimbs, and highly reduced, didactyl forelimbs $[1,2,3,4,5]$. During the Late Cretaceous, they were the dominant large carnivores in North America and Asia [4,5], with Tyrannosaurus rex being the last and the largest known member of the Tyrannosauridae [4,5]. Indeed, it is one of the largest known terrestrial carnivores; weighing up to $10,000 \mathrm{~kg}$ [6] Tyrannosaurus was as large as the largest living land animal, the African elephant (Loxodonta africana), and it was comparable in size to the smallest baleen whale, the minke (Balaenoptera acutorostrata) [7]. By comparison, the largest living terrestrial hypercarnivore, the Siberian tiger (Panthera tigris altaica) weighs just $300 \mathrm{~kg}$ [7]. Tyrannosaurus is therefore radically different from any animal living today, or any creature that has existed in the past 66 million years. Unsurprisingly, the ecology of this remarkable animal has been the subject of considerable discussion, with particular emphasis placed on the issue of whether the animal was a predator, a scavenger, or both $[4,5,8,9,10,11,12,13]$. Yet more than a century after the discovery of Tyrannosaurus, direct evidence of the animal's feeding habits is limited.

During recent museum studies of Maastrichtian dinosaurs, one of us (NRL) encountered a large theropod pedal phalanx (UCMP 137538) bearing tooth marks made by a large carnivorous dinosaur. Because Tyrannosaurus is the only large carnivore known from the late Maastrichtian of North America [14], the tooth marks and the phalanx can both be attributed to Tyrannosaurus. Subsequently, more dinosaur specimens have been found to bear Tyrannosaurus tooth marks, of which three are from Tyrannosaurus
(Table 1). We show that these specimens provide direct evidence of cannibalism in Tyrannosaurus.

\section{Materials and Methods}

Fossils were examined at the American Museum of Natural History (AMNH), the Carnegie Museum of Natural History (GM); the Museum of the Rockies (MOR), the Canadian Museum of Nature (NMC), the Royal Saskatchewan Museum (RSM), the Royal Tyrrell Museum of Palaeontology, (TMP), the University of California Museum of Paleontology (UCMP), and the Yale Peabody Museum (YPM). These include the T. rex specimens described here (UCMP 137538, MOR 902; MOR 1126; 1602) as well as all T. rex specimens in the CM, RSM, TMP, UCMP, and YPM collections, although in some cases, not all elements of a skeleton were accessible for study.

\section{Results}

Including previously described specimens, a total of 17 specimens are identified as bearing tooth marks made by Tyrannosaurus (Figure 1; Table 1). These traces consist of deep Uand V-shaped gouges and shallower scores. None of the traces described here resemble the puncture marks found on a pelvis of Triceratops, but they closely resemble the furrowed 'puncture and pull' traces that have previously been attributed to T. rex $[10,15]$.

Of these sixteen specimens, four represent Tyrannosaurus [Fig. 2]. The first is UCMP 137538, a large (13 cm long) pedal phalanx found in isolation (Fig. 2A). It is identified as a theropod by the gynglymous articular surfaces and deep collateral ligament pits, 
Table 1. Specimens showing tooth marks that are attributable to Tyrannosaurus rex, including previously described specimens (15) and specimens previously unidentified or unpublished (asterisk).

\begin{tabular}{|c|c|c|c|}
\hline Taxon & Accession/Locality Number & Toothmarked element & Provenance \\
\hline Tyrannosaurus rex & UCMP $137538^{*}$ & pedal phalanx & Hell Creek Fm., Montana, late Maastrichtian \\
\hline Tyrannosaurus rex & MOR $1126^{*}$ & skeleton & Hell Creek Fm., Montana \\
\hline Tyrannosaurus rex & MOR $920^{*}$ & skeleton & Hell Creek Fm., Montana, late Maastrichtian \\
\hline Tyrannosaurus rex & MOR $1602^{*}$ & metatarsal III & Hell Creek Fm., Montana, late Maastrichtian \\
\hline Triceratops sp. & YPM 53263* & squamosal & Lance Fm. Wyoming, late Maastrichtian \\
\hline Ceratopsidae indet. & TMP 1998.102.0005* & frill fragment & Scollard Fm., Alberta, late Maastrichtian \\
\hline Ceratopsidae indet. & MOR 799 & pelvis & Hell Creek Fm., Montana, late Maastrichtian \\
\hline Ceratopsidae indet. & NMC 53370* & ischium & $\begin{array}{l}\text { Frenchman Fm., Saskatchewan, late } \\
\text { Maastrichtian }\end{array}$ \\
\hline Ceratopsidae indet. & UCMP $130385^{*}$ & left dentary & $\begin{array}{l}\text { Hell Creek Formation, Montana, late } \\
\text { Maastrichtian }\end{array}$ \\
\hline Ceratopsidae indet. & UCMP V86061* & limb bone fragment & $\begin{array}{l}\text { Hell Creek Formation, Montana, late } \\
\text { Maastrichtian }\end{array}$ \\
\hline Edmontosaurus annectens & AMNH $5041^{*}$ & dentary & Hell Creek Fm., Montana, late Maastrichtian \\
\hline Hadrosauridae & UCMP 140601 & pedal phalanx & Hell Creek Fm., Montana, late Maastrichtian \\
\hline Hadrosauridae & UCMP uncatalogued* & metatarsal & Hell Creek Fm., Montana, late Maastrichtian \\
\hline Hadrosauridae & CM $105^{*}$ & pubis & Lance Fm., Wyoming, late Maastrichtian \\
\hline Hadrosauridae & UCMP V86026* & caudal vertebra & Hell Creek Fm., Montana, late Maastrichtian \\
\hline Thescelosaurus neglectus & MOR 1161* & Femur & Hell Creek Fm., Montana, late Maastrichtian \\
\hline Ornithischia indet. & TMP 1994.125.0102* & Rib & Scollard Fm., Alberta, late Maastrichtian \\
\hline
\end{tabular}

and is referred to Tyrannosaurus on the basis of its large size, robust construction, and provenance. Comparisons with FMNH PR 2081 [3] show that the bone is a left pedal phalanx IV-2 from a large, adult animal. The proximal end bears four gouges dorsally, and one ventrally, oriented at an oblique angle relative to the axis of the bone. The largest tooth mark is $25 \mathrm{~mm}$ long and $7 \mathrm{~mm}$ wide.

A second set of Tyrannosaurus bite marks was found on MOR 1126, a partial skeleton of Tyrannosaurus. On the left foot, pedal phalanx II-2 (Fig. 2B) bears gouges on the dorsal, lateral, medial, proximal, and distal surfaces. In one tooth mark, long striae left by denticles run through the gouge. The largest tooth mark is on the distal articular surface; it is approximately $70 \mathrm{~mm}$ long and $3.5 \mathrm{~mm}$ wide. Again, the bone comes from a large adult.

The third example comes from MOR 920, an associated skeleton of an adult Tyrannosaurus. The left humerus (Fig. 2G) bears a series of scores on its posterior surface. They are up to $36 \mathrm{~mm}$ long and $3 \mathrm{~mm}$ wide.

A fourth Tyrannosaurus specimen bearing conspecific bite marks is MOR 1602. The specimen consists of an isolated right metatarsal III missing the proximal half of the shaft (Fig. 2D). It is identified as Tyrannosaurus by its large size, the triangular shaft, and the splint-like proximal end. It bears two scores on medial surface; the larger is $44 \mathrm{~mm}$ by $4 \mathrm{~mm}$. The distal end of the bone is approximately $11 \mathrm{~cm}$ across; again the bone is from a large adult.

\section{Discussion}

The scores and gouges described here closely match the tooth marks of Tyrannosaurus [10,15], and other theropods [16] in having a $\mathrm{U}$ to $\mathrm{V}$-shaped section that tapers at either end. Given that the tooth marks are relatively deep and narrow, they were probably made by the laterally compressed teeth of the dentary and maxilla, rather than the incisiform premaxillary teeth; the tightly packed premaxillary teeth would also be expected to have left a series of closely spaced scores. An exception is UCMP 137538, where two closely spaced, subparallel gouges are found; these could conceivably have been made by premaxillary teeth.

It is extremely unlikely that any animal other than a theropod could have produced these traces. Crocodylians would not have produced the tooth marks described here. Whereas the serrated, laterally compressed teeth of theropods carve down into bone (as seen here) the subconical, unserrated teeth of crocodylians produce shallower score marks [17] or deep pits where the tooth punctures the bone [17]; such puncture marks are absent in the bones described here. Some lizards do have ziphodont teeth that can produce tooth marks resembling theropod tooth marks, notably Varanus komodensis [18]. The Hell Creek and Lance do contain a large lizard with ziphodont dentition, Palaeosaniwa [19]. However, even tooth marks made by the large $V$. komodoensis rarely exceed $1 \mathrm{~mm}$ in width [18]. Palaeosaniwa was considerably smaller than $V$. komodoensis, probably between 1 and 2 meters long, and therefore too small to have produced the traces described here. Mammals are known to gnaw on dinosaur bone [20], but mammalian gnaw traces are far smaller, and consist of closely spaced, paired tooth marks.

Insects can modify bone, but traces left by dermestid beetles are small and characterized by minute scratches left by the mandibles; termites produce meandering tunnels [21]. The large trace fossil Cubiculum [22], which is made by burrowing mayfly nymphs [23], (rather than carrion beetles), is common in the Hell Creek and Lance formations (NRL, pers. obs.) but consists of broad channels with a U-shaped section, which do not resemble the traces described here. Neither can these marks be accounted for by nonbiological mechanisms: trample marks are often seen on bones, 


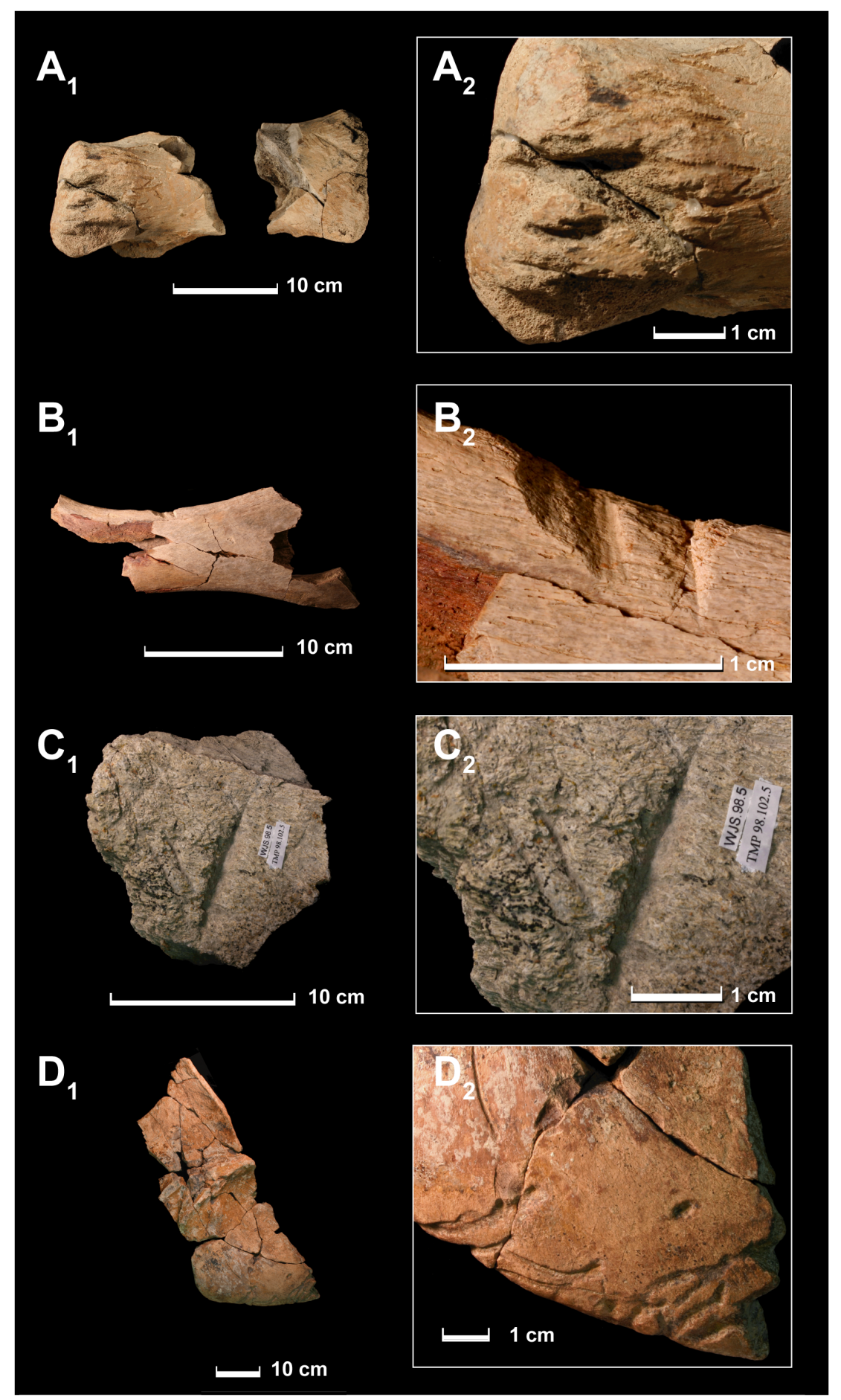

Figure 1. Tooth marks made by Tyrannosaurus rex. A, hadrosaurid metatarsal (UCMP uncatalogued) and closeup of tooth marks on distal articular surface. B, fragment of hadrosaurid pubis (CM 105) showing tooth marks on prepubic process. C, ceratopsid? frill element (TMP 1998.102.2) showing tooth mark. D, Triceratops right squamosal (YPM 53263) showing tooth marks on edge. doi:10.1371/journal.pone.0013419.g001

but these consist of numerous small and closely spaced grooves (NRL, pers. obs.). These traces do not represent tool marks made during excavation, because tools could not penetrate deeply into the fossil without shattering the brittle bone.

It is highly unlikely that a non-tyrannosaurid theropod could have made the bite marks described here. Dromaeosaurids and troodontids are known from the late Maastrichtian of North
America, but these are relatively small animals [24]. Given that tooth scores made by the much larger dromaeosaurid Deinonychus are just $1 \mathrm{~mm}$ wide [25] the small deinonychosaurs in the fauna could not have made the traces described here. Furthermore, bones bitten by dromaeosaurids are extremely rare, [25] and dromaeosaurid teeth exhibit little or no wear [24], which shows that they avoided biting into bone. In contrast, tyrannosaurids 


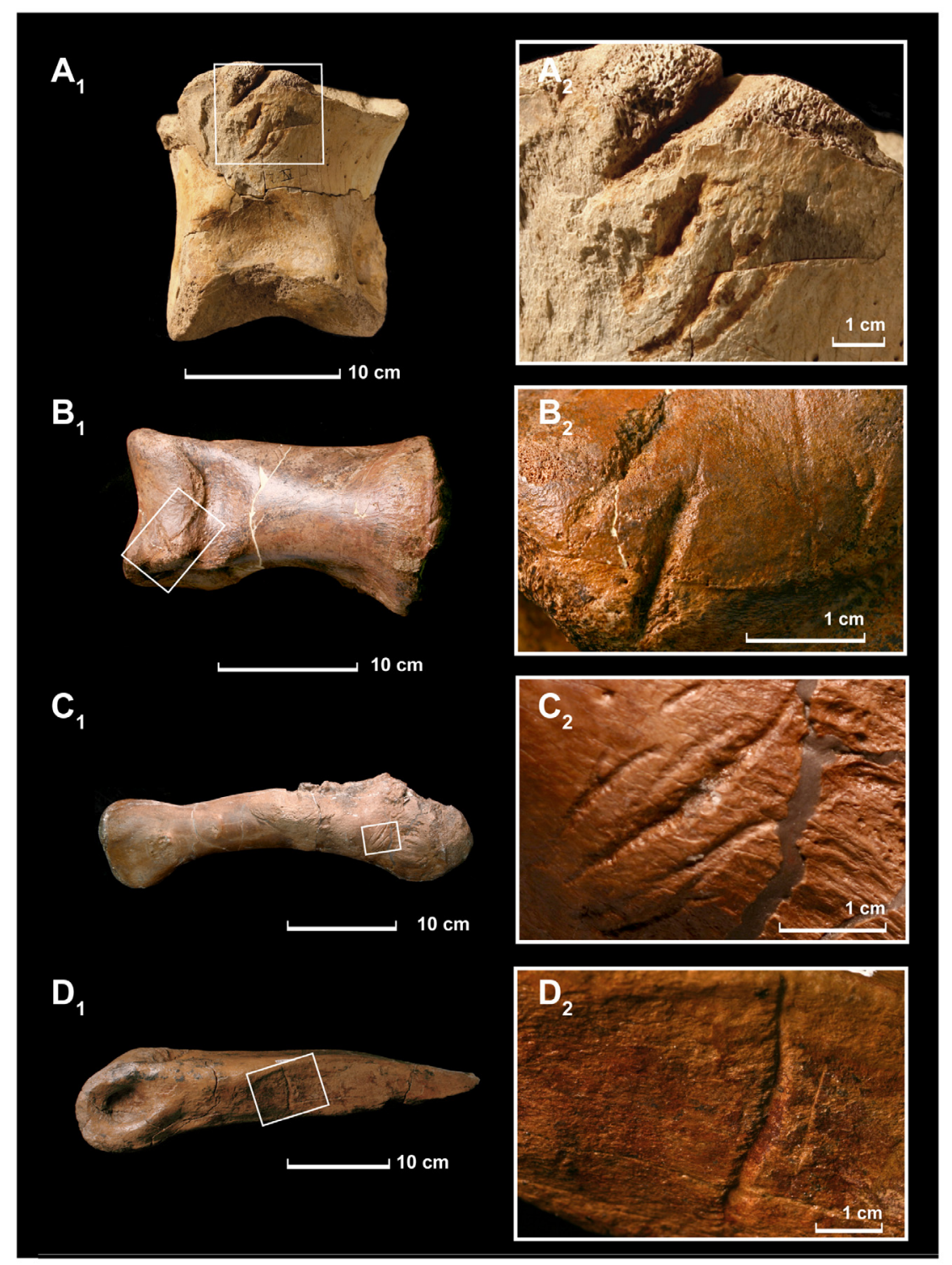

Figure 2. Tyrannosaurus rex bones bearing tooth marks made by Tyrannosaurus rex. A1, A2: UCMP 137538, pedal phalanx in dorsal view. B1, B2: Pedal phalanx, MOR 1126, dorsal view. C1, C2, Humerus of MOR 902 in caudal view. D1, D2 metatarsal III of T. rex MOR 1602, medial view. doi:10.1371/journal.pone.0013419.g002

frequently bit in to bone, as demonstrated by spalling of the teeth [26], heavy wear on the tooth apices and the carinae [27], previous identification of bite marks [15] and the presence of bone in a tyrannosaur coprolite [28].

It is usually impossible to refer tooth marks to a particular species, and here, the traces themselves preserve no distinctive features other than their size. However, Tyrannosaurus is the only large theropod known from the Late Maastrichtian of the Western Interior [14]. The holotype of "Nanotyrannus lancensis" [29] is immature and displays virtually all the features expected for a juvenile Tyrannosaurus [14,30], including a skull with a narrow snout and a broad temporal region, a deep mandible, and an elongate sagittal crest of the frontal [30]. No adults of "Nanotyrannus" are known, or juveniles of T. rex that clearly differ from "Nanotyrannus". Thus, "Nanotyrannus" is most parsimoniously considered a juvenile of Tyrannosaurus. "Nanotyrannus" does have more maxillary teeth than other specimens of $\mathcal{T}$. rex (fifteen, versus eleven to twelve for other T. rex) $[29,30,31]$ but given that this feature is highly variable within species, and even between the left and right maxillae in a single individual [31], it is insufficient to warrant the recognition of a separate species. Because there is no compelling evidence for more than one tyrannosaurid in the fauna, then by default, the traces described above can be attributed to Tyrannosaurus.

Most of the traces described here are smaller than previously described Tyrannosaurus tooth marks, which are up to $25 \mathrm{~mm}$ in width [15]. This suggests that they were made by juvenile or subadult Tyrannosaurus, although it is also conceivable that they were made by the smaller posterior teeth of a large individual. However, the broad, shallow tooth marks in MOR 1602 may have been made by a large individual that was not biting at full force.

We argue that these traces result from feeding, rather than intraspecific combat. First, these traces would have been difficult to inflict on a live animal. In the case of MOR 1126, bite marks occur on both the proximal and distal ends of the bone and the shaft, suggesting that the bone was bitten two or three times. It 
seems unlikely that a small Tyrannosaurus would be allowed to repeatedly bite a much larger individual several times on a single toe. In the case of the metatarsal, MOR 1602, the tooth mark runs across the bone's articulation with metatarsal II. Because the metatarsus was tightly bound in life, it would have been difficult to inflict such a mark on the articulated foot of a living animal. Furthermore, fighting animals would be expected to inflict wounds to the head [32] or vulnerable areas such as the neck and flanks, and not the feet or arms. Finally, the absence of healing in any of these specimens is also consistent with the hypothesis that the tooth marks were made on carcasses.

Tyrannosaurus therefore seems to have been an indiscriminate and opportunistic feeder, feeding not only on herbivorous dinosaurs, but also on members of its own species. The traces described here likely result from opportunistic scavenging, and were probably made after most of the flesh and organs had been removed from the carcass. Presumably, an animal feeding on a fresh kill would instead be expected to focus on viscera and large muscle masses, which would provide more food with less effort. For feet, toes, and arms to be an appealing source of food, most of the carcass must already have been defleshed. It is somewhat perplexing why so few tooth marks are found on other elements, however. Tooth marks made by Komodo dragons [18] and extant carnivorans [33] tend to be concentrated on elements bearing more meat, and it is therefore surprising not to find more traces made during the initial defleshing of the carcass.

While we interpret these traces as the results of scavenging, we cannot entirely rule out the possibility that these traces result from an individual slowly consuming a kill over an extended period of time. It does seem improbable that Tyrannosaurus routinely hunted full-grown members of its own species; however, it is possible that intraspecific combat led to casualties, with the dead becoming a convenient source of food for the victors. Still, compelling evidence for predation in Tyrannosaurus remains elusive. Healed injuries in herbivorous dinosaurs are consistent with failed predation $[11,13]$ but it is debatable whether these traces are actually the results of bites, or some other form of trauma.

Four examples of cannibalism are known from a relatively limited sample of tooth-marked bones. Given this, cannibalism must have been common in Tyrannosaurus. If anything, the frequency of cannibalism is easily underestimated, for several reasons. First, the act of feeding on a carcass tends to destroy the evidence, because bones may be ingested, broken up, or dragged off and left to weather away out in the open. Second, cannibalism

\section{References}

1. Osborn HF (1905) Tyrannosaurus and other Cretaceous carnivorous dinosaurs. Bulletin of the American Museum of Natural History 35: 733-771.

2. Lambe LM (1917) The Cretaceous Theropodous Dinosaur Gorgosaurus. Canada Department of Mines Geological Survey Memoir 100: 1-84.

3. Brochu CA (2002) Osteology of Tyrannosaurus rex: insights from a nearly complete skeleton and high-resolution computed tomographic analysis of the skull. Journal of Vertebrate Paleontology, Memoirs 7: 1-138.

4. Holtz TR (2004) Tyrannosauroidea. In: Weishampel DB, Dodson P, Osmolska H, eds. The Dinosauria. Second ed. Berkeley: University of California Press. pp 111-136.

5. Paul GS (2008) Extreme lifestyles and habits of the gigantic tyrannosaurid superpredators of the Late Cretaceous of North America and Asia. In: Larson P, Carpenter K, eds. Tyrannosaurus rex: The Tyrant King. Bloomington: Indiana Univ. Press. pp 354-368.

6. Therrien F, Henderson DM (2007) My theropod is bigger than yours... or not: estimating body size from skull length in theropods. Journal of Vertebrate Paleontology 27: 108-115.

7. Nowak RM (1991) Walker's Mammals of the World. Baltimore: Johns Hopkins University Press. 1629 p.

8. Paul GS (1988) Predatory Dinosaurs of the World. New York: Simon and Schuster. $464 \mathrm{p}$.

9. Horner JR, Lessem D (1993) The Complete T. rex. New York: Simon and Schuster. can only be observed on a carcass where the animals leave tooth marks; where Tyrannosaurus fed around the bones, such events would not be recognized. Third, many Tyrannosaurus skeletons are mounted, preventing detailed examination of the bones for tooth marks. Fourth, although we examined as many bones in as many museums as possible, it was not possible to examine all specimens of Tyrannosaurus in all museums. Given this, it is perhaps surprising to find even a single instance of cannibalism, let alone multiple examples.

Recent studies have questioned whether cannibalism was widespread in dinosaurs [34], but the traces described here show that Tyrannosaurus was indisputably a cannibal. The only other dinosaur known to have engaged in cannibalism is the abelisaurid Majungatholus [16], however theropod tooth marks also occur on tyrannosaurid bones from the Dinosaur Park Formation [32,35]. Because two tyrannosaurids- Gorgosaurus and Daspletosaurus- occur here, it is impossible to definitively state that these traces represent cannibalism [34]. However, because Gorgosaurus outnumbers Daspletosaurus by three-to-one in this environment [36], most of the bones and feeding traces probably represent Gorgosaurus and therefore it is probable that at least some of these traces represent cannibalism.

Cannibalism is common in nature [37], particularly among large carnivores, including bears [38,39,40], hyenas [41], large felids [42,43], Komodo dragons [44], and crocodylians [45,46]. Notably, most documented cases of cannibalism in large carnivores involve predation, rather than scavenging. Cannibalism is especially common in the American alligator, and may account for more than half of the juvenile mortality each year [46]. Given that cannibalism is known in Tyrannosaurus, Majungatholus and many extant, large-bodied carnivores, this behavior is likely to have been widespread in large, carnivorous dinosaurs.

\section{Acknowledgments}

We thank A. Henrici, W. Joyce, P. Holroyd, Brandon Strilisky, and Margaret Feuerstack for assistance with collections. Thanks also to Thomas Holtz and Stephanie Drumheller for reviews that greatly improved this paper.

\section{Author Contributions}

Conceived and designed the experiments: NL JRH. Performed the experiments: NL JRH. Analyzed the data: NLJRH GME PC. Contributed reagents/materials/analysis tools: JRH. Wrote the paper: NL GME.

10. Erickson GM, Van Kirk SD, Su J, Levenston ME, Caler WE, et al. (1996) Biteforce estimation for Tyrannosaurus rex from tooth-marked bones. Nature 382: 706-708.

11. Carpenter K (1998) Evidence of predatory behavior by carnivorous dinosaurs. Gaia 15: 135-144.

12. Holtz TR, Jr. (2008) A critical reappraisal of the obligate scavenging hypothesis for Tyrannosaurus rex and other tyrant dinosaurs. In: Larson P, Carpenter K, eds. Tyrannosaurus rex: The Tyrant King. Bloomington: Indiana Univ. Press. pp 370-396.

13. Happ J (2008) An analysis of predator-prey behavior in a head-to-head encounter between Tyrannosaurus and Triceratops. In: Larson P, Carpenter K, eds. Tyrannosaurus rex: The Tyrant King. Bloomington: Indiana Univ. Press. pp 354-368.

14. Carr TD, Williamson TE (2004) Diversity of late Maastrichtian Tyrannosauridae (Dinosauria: Theropoda) from western North America. Zoological Journal of the Linnean Society 142: 479-523.

15. Erickson GM, Olson KH (1996) Bite marks attributable to Tyrannosaurus rex: preliminary description and implications. 16: 175-178.

16. Rogers RR, Krause DW, Curry Rogers K (2003) Cannibalism in the Madagascan dinosaur Majungatholus atopus. Nature 422: 515-518.

17. Njau JK, Blumenschine RJ (2005) A diagnosis of crocodile feeding traces on larger mammal bone, with fossil examples from the Plio-Pleistocene Olduvai Basin, Tanzania. Journal of Human Evolution 50: 142-162. 
18. D'Amore DC, Blumenschine RJ (2009) Komodo monitor (Varanus komodoensis) feeding behavior and dental function reflected through tooth marks on bone surfaces as the application to ziphodont paleobiology. Paleobiology 35: 525-552.

19. Estes R (1964) Fossil vertebrates from the Late Cretaceous Lance Formation, Eastern Wyoming. University of California Publications, Department of Geological Sciences 49: 1-180.

20. Longrich NR, Ryan MJ (2010) Mammalian tooth marks on the bones of dinosaurs and other Late Cretaceous vertebrates. Palaeontology 53: 703-709.

21. Britt BB, Scheetz RD, Dangerfield A (2008) A suite of dermestid beetle traces on dinosaur bone from the Upper Jurassic Morrison Formation, Wyoming, USA. Ichnos 15: 59-71.

22. Roberts EM, Rogers RR, Foreman BZ (2007) Continental insect borings in dinosaur bone: examples from the Late Cretaceous of Madagascar and Utah. Journal of Paleontology 81: 201-208.

23. Thenius $\mathrm{vE}$ (1979) Lebensspuren von ephemeropteren-larven aus dem JungTertiär des wiener beckens. Annalen Naturhistorischen Museum Wien 82: 177-188.

24. Longrich NR (2008) Small theropod teeth from the Lance Formation of Wyoming. In: Sankey JT, Baszio S, eds. The Unique Role of Vertebrate Microfossil Assemblages in Paleoecology and Paleobiology:. Indiana: University Press. pp 135-158.

25. Gignac PM, Makovicky PJ, Erickson GM, Walsh RP (2010) A description of Deinonychus antirrhopus bite marks and estimates of bite force using tooth indentation simulations. Journal of Vertebrate Paleontology 30: 1169-1177.

26. Schubert BW, Ungar PS (2005) Wear facets and enamel spalling in tyrannosaurid dinosaurs. Acta Palaeontologica Polonica 50: 93-99.

27. Farlow JO, Brinkman D (1994) Wear surfaces on the teeth of tyrannosaurs. In: Rosenberg GD, Wolberg DL, eds. The Paleontological Society Special Publication; 1994. Knoxville: Dept. Geological Sciences, Univ. of Tennessee. pp $165-175$.

28. Chin K, Tokaryk TT, Erickson GM, Calk LC (1998) A king-sized theropod coprolite. Nature 393: 680-682.

29. Bakker R, Williams M, Currie PJ (1988) Nanotyrannus, a new genus of pygmy tyrannosaur, from the latest Cretaceous of Montana. Hunteria 1: 1-30.

30. Carr TD (1999) Craniofacial ontogeny in Tyrannosauridae (Dinosauria, Coelurosauria). Journal of Vertebrate Paleontology 19: 497-520.
31. Currie PJ (2003) Cranial anatomy of tyrannosaurid dinosaurs from the Late Cretaceous of Alberta, Canada. Acta Palaeontologica Polonica 48: 191-226.

32. Tanke DH, Currie PJ (1998) Head-biting behavior in the theropod dinosaurs: paleopathological evidence. Gaia 15: 167-184.

33. Shipman P (1986) Scavenging or hunting in early hominids: theoretical framework and tests. American Anthropologist 88: 27-43.

34. Nesbitt SJ, Turner AH, Erickson GM, Norell MA (2006) Prey choice and cannibalistic behavior in the theropod Coelophysis. Biology Letters 2: 611-614.

35. Jacobsen AR (1998) Feeding behavior of carnivorous dinosaurs as determined by tooth marks on dinosaur bones. Historical Biology 13: 17-26.

36. Currie PJ, Russell DA (2005) The geographic and stratigraphic distribution of articulated and associated dinosaur remains. In: Currie PJ, Koppelhus EB, eds. Dinosaur Provincial Park: a spectacular ancient ecosystem revealed. Bloomington: Indiana University Press. pp 202-220.

37. Fox LR (1975) Cannibalism in natural populations. Annual Reviews of Ecology and Systematics 6: 87-106.

38. Tietje WD, Pelchat BO, Ruff RL (1986) Cannibalism of denned black bears. Journal of Mammalogy 67: 762-766.

39. Mattson DJ, Knight RR, Blanchard BM (1992) Cannibalism and predation on black bears by grizzly bears in the Yellowstone ecosystem. Journal of Mammalogy 73: 422-425.

40. Amstrup SC, Stirling I, Smith TS, Perham C, Thiemann GW (2006) Recent observations of intraspecific predation and cannibalism among polar bears in the southern Beaufort Sea. Polar Biology 29: 997-1002.

41. Kruuk H (1972) The Spotted Hyena: A Study of Predation and Social Behavior: University of Chicago Press. 335 p.

42. Lesowski J (1963) Two observations of cougar cannibalism. Journal of Mammalogy 44: 586.

43. Eloff FC (1984) Food ecology of the Kalahari lion Panthera leo. Koedoe 27: 249-258.

44. Auffenberg W (1981) The Behavioral Ecology of the Komodo Monitor. Gainesville: University Presses of Florida.

45. Pooley AC, Ross CA (1989) Mortality and Predators. In: Ross CA, ed. Crocodiles and Alligators. New York: Facts on File. pp 92-101.

46. Rootes WL, Chabreck RH (1993) Cannibalism in the American alligator. Herpetologica 49: 99-107. 